\title{
Colistin, Polymyxin B and Tigecycline Suspectibility to Metallo Betalactamase Producing Acinetobacter Baumannii Isolated From Tertiary Health Care Hospital
}

\author{
Venkata sarada ${ }^{1, *}$, Ratna $\operatorname{Rao}^{1}$, Ratna $\operatorname{mani}^{1}$, K V Ramana ${ }^{2}$ \\ ${ }^{1}$ Department of microbiology, Apollo health city, Jubilee Hils, Hyderabad, Andhra Pradesh,India \\ ${ }^{2}$ Department of microbiology, Prathima Institute of Medical Sciences, Karimnagar, Andhrapradesh, India \\ *Corresponding author: venkatasaradaa@yahoo.com
}

Received January 17, 2014; Revised March 18, 2014; Accepted March 19, 2014

\begin{abstract}
Acinetobacter baumannii have emerged as important nosocomical pathogens especially in intensive care patients. Carbapenems are the choice of drug for their treatment but they started developing resistance to carbapenems predominatantly by producing Metallo beta-lactamases (MBL). Treatment of such carbapenem resistant Acinetobacter has led to reintroduction of polymyxins like colistin, polymyxin B and newer tetracycline group of drugs like tigecycline. As there were limited studies in on Minimum inhibitory concentrations (MIC) of MBL producing Acinetobacter to polymyxins and tigecyclines from india, the present study was undertaken. MBL detection was done by combined disc test with imipenem and EDTA. MIC of the drugs was determined by Agar dilution method. MIC50 and MIC90 of tigecycline were found to be $0.5 \mu \mathrm{g} / \mathrm{ml}$ and $1 \mu \mathrm{g} / \mathrm{ml}$ respectively. Suseptibility MIC ranges for tigecycline were found to be 0.5 to $2 \mu \mathrm{g} / \mathrm{ml}$. Resistance rates for tigecycline were found to be $6 \%$. MIC50 and MIC90 of colistin was found to be $2 \mu \mathrm{g} / \mathrm{ml}$. Susceptibility MIC ranges for colistin were found to be 0.25 to $1 \mu \mathrm{g} / \mathrm{ml}$. MIC50 and MIC90 of polymyxinB were found to be $1 \mu \mathrm{g} / \mathrm{ml}$ and $2 \mu \mathrm{g} / \mathrm{ml}$ respectively. Susceptibility MIC ranges for polymyxin B were found to be between 0.5 to $2 \mathrm{ug} / \mathrm{ml}$. The susceptibility rates with colistin and polymyxin B were found to be $99.2 \%$ and $100 \%$ respectively. Polymyxin B and colistin are very good drugs of choice for treatment of MBL producing Acinetobacter baumannii with $0.8 \%$ and $0 \%$ resistance rates. Though good sensitivity was noticed with tigecycline, we found $6 \%$ resistance rate.
\end{abstract}

Keywords: Acinetobacter baumannii, Metallo beta-lactamases(MBL), colistin, polymyxin B, Minimum inhibitory concentrations (MIC), tigecycline

Cite This Article: Venkata sarada, Ratna Rao, Ratna mani, and K V Ramana, “Colistin, Polymyxin B and Tigecycline Suspectibility to Metallo Betalactamase Producing Acinetobacter Baumannii Isolated From Tertiary Health Care Hospital.” American Journal of Microbiological Research, vol. 2, no. 2 (2014): 60-62. doi: 10.12691/ajmr-2-2-3.

\section{Introduction}

Acinetobacter species are opportunistic pathogens causing nosocomial infections especially among patients admitted to intensive care units (ICUs) associated with mortality and morbidity [1]. Carbapenems have remained as drugs of choice for treatment of Acinetobacter infection. Over usage of carbapenems has to development of Metallo beta lactamase (MBL) producing bacteria [4]. Treatment of infections caused by MBL producing Acinetobacter has become difficult as few antimicrobial agents remain active against these pathogens $[2,3]$. The increased incidence of nosocomial infections by multidrug-resistant Acinetobacter spp creates demand for reintroduction of older antimicrobials like polymyxins and newer tetracyclines like tigecycline $[5,6]$.

Polymyxins, are a group of polypeptide antibiotics that consists of 5 chemically different compounds (polymyxins A-E) that mainly target cytoplasmic membrane of bacterial cell [8], Polymyxins (colistin and polymyxin B) have not been used for many years because of avalibility of less toxic antibiotics. Gram-negative bacteria that are resistant to the aminoglycosides, beta-lactams, and fluoroquinolones are often susceptible to the polymyxins $[7,11]$.

Tigecycline is a glyclycycline antibiotic having similar structure as tetracyclines. It inhibits protein synthesis by binding to 30s ribosomal subunit[9]. In comparison with tetracyclines, tigecycline binds to corresponding ribosomal sites with greater affinity, and irrespective of the presence of mutations that confer resistance to tetracycline's [10]. Tigecycline shows greater activity against multidrug resistant gram-negative bacteria such as Acinetobacter baumannii, Stenotrophomonas maltophilia and Klebsiella pneumoniae [9].

Though much of data regarding Minimum inhibitory concentration of polymyxins and tigecyclines was available from studies of other countries, very less data is available from India. The objective of this study was to assess the in vitro susceptibilities of polymyxins and 
tigecycline to metallo beta lactamase producing Acinetobacter baumannii, and to know local susceptibility (MIC) ranges that can be important prerequisite for appropriate use of antibiotics.

\section{Materials and Methods}

\subsection{Bacterial Strains}

The present study was done in the Department of Microbiology at Apollo Health City; Hyderabad. A total of 102 strains of carbapenem resistant Acinetobacter baumannii were collected from various specimens of nosocomial infections from July 2008 to Jan 2010. Species confirmation was done by semi- automated system MINI API ID 32 GN(Biomerieux USA). All the isolates were stored at $-20^{\circ} \mathrm{C}$ in glycerol trypticase soya broth.

\subsection{MBL Detection}

Phenotypic detection of MBLs were done by IPMEDTA Disk Synergy test proposed by Young D et al [12].

\subsection{Sensitivity Testing}

Susceptibility testing to various antibiotics like Gentamicin, to Amikacin, Ceftazidime, Ciprofloxacin, Gatifloxacin, Cefepime, Piperacillin/ tazobactam, Aztreonem, Amphicillin/ sulbactam, Meropenum and Imipenum was done by disk diffusion test(Hi-media).

\subsection{MIC Testing}

The MIC of each drug were detected by Agar dilution method. Stocks of colistin, polymyxin and tigecycline were prepared. Serial two fold dilutions of each drug were prepared. The dilutions ranged from $32 \mu \mathrm{g}$ to $0.125 \mu \mathrm{g}$. These dilutions were mixed into $20 \mathrm{ml}$ of Muller- Hinton medium and poured into Petri dishes. $3 \mu$ l of inoculums was seeded onto the plate using a micropipette at specifically marked columns of different test organisms. The plates were kept for overnight incubation at $37^{\circ} \mathrm{C}$ and observed for growth $[13,16,17]$. ATCC controls were included in the study. MIC ranges for each drug were studied as MIC90 and MIC50.

\section{Results}

Out of 102 isolates of Acinetobacter baumannii, 56 were isolated from endotracheal secretions, 15 from purulent discharge, 12 from blood, 10 from body fluids, 8 from sputum, and 1 from urine. All the isolates were found to be MBL producers phenotypically by double disk synergy test (imipenum and EDTA synergy test).

Of the 102 isolates of Acinetobacter baumannii, 83.3\% were resistant to Gentamicin, 94\% to Amikacin, 99\% to Ceftazidime, 98\% to Ciprofloxacin, 27\% to Gatifloxacin, 93\% to Cefepime, 91.\% to Piperacillin/ tazobactam, 98\% to Aztreonem $84 \%$ to Amphicillin/ sulbactam,100\% to Meropenum and 95\% to Imipenum.

Table 1. Number of isolates of Acinetobacter baumannii susceptible at various MIC ranges to colistin, polymyxin B and tigecycline

\begin{tabular}{|c|c|c|c|c|c|c|c|c|c|c|}
\hline Antibiotics & No of isolates tested & $\begin{array}{r}0.125 \\
\mu \mathrm{g} / \mathrm{ml}\end{array}$ & $\begin{array}{c}0.25 \\
\mu \mathrm{g} / \mathrm{ml}\end{array}$ & $\begin{array}{c}0.5 \\
\mu \mathrm{g} / \mathrm{ml}\end{array}$ & $\begin{array}{c}1 \\
\mu \mathrm{g} / \mathrm{ml}\end{array}$ & $\begin{array}{c}2 \\
\mu \mathrm{g} / \mathrm{ml}\end{array}$ & $\begin{array}{c}4 \\
\mu \mathrm{g} / \mathrm{ml}\end{array}$ & $\begin{array}{c}8 \\
\mu \mathrm{g} / \mathrm{ml}\end{array}$ & $\begin{array}{c}16 \\
\mu \mathrm{g} / \mathrm{ml}\end{array}$ & $\begin{array}{c}32 \\
\mu \mathrm{g} / \mathrm{ml}\end{array}$ \\
\hline Colistin & 102 & 1 & 0 & 5 & 35 & 60 & 0 & 0 & 1 & 0 \\
\hline Polymyxin B & 102 & 1 & 1 & 8 & 52 & 40 & 0 & 0 & 0 & 0 \\
\hline Tigecycline & 102 & 6 & 7 & 62 & 14 & 7 & 1 & 2 & 1 & 2 \\
\hline
\end{tabular}

Table 2. MIC 50 and MIC 90 values of colistin, polymyxin and tigecycline against MBL producing Acinetobacter baumannii

\begin{tabular}{|c|c|c|c|c|}
\hline Antibiotics & $\begin{array}{c}\text { MIC } 50 \\
\mu \mathrm{g} / \mathrm{ml}\end{array}$ & $\begin{array}{c}\text { MIC 90 } \\
\mu \mathrm{g} / \mathrm{ml}\end{array}$ & \% susceptibility & Break points \\
\hline Colistin & 2 & 2 & 99.2 & $\leq 2 \mu \mathrm{g} / \mathrm{ml}$ \\
\hline Polymyxin B & 1 & 2 & 100 & $\leq 2 \mu \mathrm{g} / \mathrm{ml}$ \\
\hline Tigecycline & 0.5 & 1 & $94.1 \%$ & $\leq 2 \mu \mathrm{g} / \mathrm{ml}$ \\
\hline
\end{tabular}

Of the total isolates maximum number isolates were susceptible to Colistin, Polymyxin and Tigecycline at 2 $\mu \mathrm{g} / \mathrm{ml}, 1 \mu \mathrm{g} / \mathrm{ml}$ and $0.5 \mu \mathrm{g} / \mathrm{ml}$ respectively.

MIC 50 and MIC 90 of colistin, polymyxin, tigecycline were found to be $2 \mu \mathrm{g} / \mathrm{ml}$ and $2 \mu \mathrm{g} / \mathrm{ml}, 1 \mu \mathrm{g} / \mathrm{ml}$ and $2 \mu \mathrm{g} / \mathrm{ml}$, 0.5 and $1 \mu \mathrm{g} / \mathrm{ml}$ respectively

\section{Discussion}

In our study high resistance was observed to aminoglycosides, third and fourth generation cephalosporins, penicillins and even to monobactums and Amphicillin / sulbactum. $73 \%$ of isolates were sensitive to Gatifloxacin but only $2 \%$ were found sensitive to Ciprofloxacin. Though all the isolates were resistant to meropenem, 5\% of the isolates were found susceptible to imipenem.

In our study MIC 90 of colistin was found to be $2 \mu \mathrm{g} / \mathrm{ml}$ similar to the studies from Singapore and EUCAST studies [18,19,20,22]. MIC 50 of colistin was also found to be $2 \mu \mathrm{g} / \mathrm{ml}$ which was little higher than other studies $1 \mu \mathrm{g} / \mathrm{ml} \quad[18,19]$. 99\% of the isolates were found susceptible to colistin with MIC break points $\mathrm{S} \leq 2$ and $\mathrm{R}>2$ [16]. Maximum isolates were found to be sensitive at $2 \mu \mathrm{g} / \mathrm{ml}$ with sensitive MIC ranges $0.5-2 \mu \mathrm{g} / \mathrm{ml}$. Only 1 isolate was found resistant to colistin. Resistance rates were almost similar to studies from Turkey [6] and Thailand [11].

MIC 50 and MIC 90 of Polymyxin B were found to be $1 \mu \mathrm{g} / \mathrm{ml}$ and $2 \mu \mathrm{g} / \mathrm{ml}$ similar to the sentry report USA $[21,22]$. Maximum isolates were found sensitive at $1 \mathrm{ug} / \mathrm{ml}$ with susceptible MIC range $0.25-2 \mu \mathrm{g} / \mathrm{ml}$. All the isolates were found sensitive to Polymyxin with MIC break points $\leq 2 \mu \mathrm{g} / \mathrm{ml}$ [23]. We noticed 0\% resistance to Polymyxin B where as sentry report USA reported $2.5 \%$ resistance [21].

In our study MIC50 and MIC90 of tigecycline were found to be 0.5 and 1 respectively similar to the studies in Bangkok [14], lower than the MIC50 and MIC90 2 $\mu \mathrm{g} / \mathrm{ml}$ 
from the studies of Spain [15] by dilution methods. Maximum isolates were found susceptible at $0.5 \mu \mathrm{g} / \mathrm{ml}$ with sensitive MIC range .125 to $2 \mu \mathrm{g} / \mathrm{ml}$. Only 6 isolates were found to be resistant to tigecycline. Resistance rates were similar to the from Spain 8\% [15] and less when compared to other studies from Turkey 25.8\% [6]. The lower resistance rates may be due to recent introduction of tigecycline in India. The susceptibility rates for tigecycline were found to be $94 \%$ with MIC break points $\leq 2 \mu \mathrm{g} / \mathrm{ml}$ [25]. As there are no approved standard MIC break points for Acinetobacter baumannii to tigecycline in the present study we took provisional MIC break points as $\leq 2 \mu \mathrm{g} / \mathrm{ml}$ (Wyeth Research, personal communication) [15,20].

\section{Conclusion}

In summary colistin and polymyxin B are very good drugs of choice for treatment of infections caused by Acinetobacter baumannii. Due to toxicity of polymyxins, tigecycline is the next better drug of choice with $94 \%$ susceptibility rates.

\section{Acknowledgements}

We acknowledge the support of Apollo Hospitals and DR NTR University of Health Sciences.

\section{References}

[1] Maria C. B. Tognim, Ana C. Gales (july 2006) Dissemination of IMP-1 Metallo-b-Lactamase-Producing Acinetobacter Species in a Brazilian Teaching Hospital. Infect. Control Hosp. Epidemiol. 27: 742-747.

[2] LisaA.Kroeger,Laurie B.Hovde (sept.2007) colistin Methanesulfonate against Multi drug resistant Acinetobacter baumanni in an In vitro Pharmacodynamic model. Antimicrob. Agents Chemother 51: 3431-3433.

[3] Quale J, Bratu S, Landman (2003). Molecular epidemiology and mechanisms of carbapenem resistance in Acinetobacter baumannii endemic in New York City. Clin Infect Dis 37: 214-220.

[4] Brand M, Wright Edward H(2008). Current Perspectives on Extended-Spectrum Beta-Lactamase-Producing Gram-Negative Bacilli. Journal of Pharmacy Practice 21: 338-345.

[5] Alexandr Nemec \& lenie dijshoorn (2010). Variations in colistin suspectibility among different species of the genus Acinetobacter. Antimicrob. Agents Chemother 65: 365-369.

[6] M.Dizbay,A.Altuncekic (2008). Colistin and tigecycline susceptibility among multidrug-resistant Acinetobacter baumannii isolated from ventilator-associated pneumonia. Int J Antimicrob Agents 32: 29-32.
[7] ME Evans, DJ Feola, RP Rapp(1999). Polymyxin B sulfate and colistin: old antibiotics for emerging multiresistant gram-negative bacteria. Ann Pharmacother 33: 960-967.

[8] Matthew E, Falagas, Sofia K(2005) Colistin: The Revival of Polymyxins for the Management of Multidrug-Resistant GramNegative Bacterial Infections. Clin Infect Dis 40: 1333-41.

[9] K. Gupta, S. Kaushal, S. C. Chopra (2006) Tigecycline a novel glyclycycline antibiotic.Indian J Pharmacol 38: 218-219.

[10] Drosos E. Karageorgopoulos, Theodore Kelesidis (2008) Tigecycline for the treatment of multidrug-resistant (including carbapenem-resistant) Acinetobacter infections: a reviewof the scientific evidence. J Antimicrob Chemother 62: 45-55.

[11] Thanaporn Hortiwakul, Pantip Chayakul, (2009). In Vitro Activity of Colistin, Fosfomycin, and Piperacillin/tazobactam Against Acinetobacter baumannii and Pseudomonas aeruginosa in Songklanagarind Hospital, Thailand. J Infect Dis Antimicrob Agents 26 : 91-96.

[12] Marchiaro P, Mussi MA, Viale AM Villa(2005). Sensitive EDTA based Microbiological assays for detection of metallo $\beta$ lactamases in non fermentative Gram negative bacteria. J. Clin. Microbiol. 43:5648-5652.

[13] Ramana KV, Mohanty SK, Wilson CG(2009). Staphylococcus aureus colonization of anterior nares of school going children. Indian J Pediatr 76:813-816.

[14] Visanu Thamlikitkul, Surapee Tiengrim (2007).High tigecycline resistance in multidrug-resistant Acinetobacter baumannii J Antimicrob Chemother 60: 177-178.

[15] María Eugenia Pacho, Manuel Enrique (2004).Activity of Tigecycline (GAR-936) against Acinetobacter baumannii Strains, Including Those Resistant to Imipenem. Antimicrob. Agents Chemother 48: 4479-4481.

[16] Wayne, Pa (2000). Methods for dilution antimicrobial susceptibility tests for bacteria that grow aerobically. National Committee for Clinical LaboratoryStandards,.5th ed. Approved standard M7-A5.

[17] Wayne, Pa. (2001). Performance standards for antimicrobial susceptibility testing. National Committee for Clinical Laboratory Standards. Eleventh informational supplement. M100-S11.

[18] Thean Yen Tan and Lily Siew Yong Ng(2006), Comparison of three standardized disc susceptibility testing methods for colistin. J Antimicrob Chemother 58: 864-867.

[19] Colistin, Rationale for the EUCAST clinical breakpoints(2010), version 1.0.

[20] Drosos E. Karageorgopoulos, Theodore Kelesidis (2008). Tigecycline for the treatment of multidrug-resistant (including carbapenem-resistant) Acinetobacter infections: a review of the scientific evidence. J Antimicrob Chemother 62: 45-55.

[21] A. C. Gales, R. N. Jones, H. S. Sader (2006) Global assessment of the antimicrobial activity of polymyxin B against 54731 clinical isolates of Gram-negative bacilli: report from the SENTRY antimicrobial surveillance programme (2001-2004). Clin Microbiol Infect 12 : 315-321.

[22] Ana c. gales, adriana o. reis and ronald $\mathrm{n}(2001)$. jones1Contemporary Assessment of Antimicrobial Susceptibility Testing Methods for Polymyxin B and Colistin: Review of Available Interpretative Criteria and Quality Control Guidelines. J clin microbiol 39: 183-190.

[23] Alexandre Prehn Zavascki, Luciano Zubaran Goldani, Jian Li4 and Roger L. Nation4 (2007). Polymyxin B for the treatment of multidrug-resistant pathogens: a critical review. J Antimicrob Chemother 60: 1206-1215. 